\title{
Congenital systemic candidiasis: a comprehensive literature review and meta-analysis of 44 cases
}

\author{
Tiberiu Augustin GeorgesCu ${ }^{1,2)}$, Antonia-Carmen Lisievici ${ }^{2)}$, Octavian MunTEanu ${ }^{3,4}$,

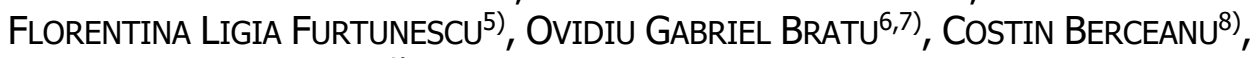 \\ ROXANA ELENA BOHÎLTEA ${ }^{9)}$
}

\author{
1) Department of Pathology, Polizu Clinical Hospital, Bucharest, Romania \\ 2) Department of Pathology, Carol Davila University of Medicine and Pharmacy, Bucharest, Romania \\ 3) Department of Obstetrics and Gynecology, University Emergency Hospital, Bucharest, Romania \\ 4) Department of Anatomy, Carol Davila University of Medicine and Pharmacy, Bucharest, Romania \\ ${ }^{5)}$ Department of Public Health and Management, Carol Davila University of Medicine and Pharmacy, Bucharest, \\ Romania \\ 6) Department of Urology, Dr. Carol Davila Central Military Emergency University Hospital, Bucharest, Romania \\ 7) Department of Urology, Carol Davila University of Medicine and Pharmacy, Bucharest, Romania \\ ${ }^{8)}$ Department of Obstetrics and Gynecology, University of Medicine and Pharmacy of Craiova, Romania \\ 9) Department of Obstetrics and Gynecology, Carol Davila University of Medicine and Pharmacy, Bucharest, \\ Romania
}

\begin{abstract}
Systemic candidiasis is a frequent complication in neonatal units, but congenital systemic candidiasis is an unusual diagnosis, observed in both full-term and preterm infants, with less than 50 cases reported to date. Congenital candidiasis presents with a wide spectrum of symptoms, ranging from diffuse skin eruptions to severe systemic disease, resulting in fetal demise or early neonatal death. Although management guidelines have been published almost two decades ago, due to the rarity of this type of infection, conclusive recommendations are difficult to establish, since they are based on anecdotal experience. In this paper, we present a comprehensive meta-analysis of the current scientific knowledge regarding congenital candidiasis, which spans 54 years and includes a total of 44 cases.
\end{abstract}

Keywords: congenital systemic candidiasis, cutaneous congenital candidiasis, neonatal death, preterm birth, stillbirth, preterm premature rupture of the membranes.

\section{Introduction}

Candidiasis is defined as infection with fungi of the Candida genus. Congenital candidiasis is a rare entity in which intrauterine infection with Candida spp. is evident at birth. It may be localized (congenital cutaneous candidiasis), presenting as an extensive skin rash, which eventually results in widespread desquamation, or generalized (congenital systemic candidiasis), which usually lacks cutaneous involvement and presents with respiratory distress, meningitis, sepsis, and death.

Unlike nosocomial systemic candidiasis, which is a common problem in neonatal intensive care units worldwide, congenital systemic candidiasis is an extremely rare disease reported both in full-term and preterm infants, with less than 50 cases published in the medical literature to date.

Candida vaginitis occurs in approximately $25 \%$ of all pregnancies, without causing any obstetric complications [1]. Rarely, ascending infection from the lower maternal genital tract may occur, resulting in placental candidiasis. The extent of infection is usually limited to fungal chorioamnionitis and funisitis, with no fetal involvement. When it occurs, congenital neonatal infection is usually limited to cutaneous involvement, but life-threatening disseminated candidiasis may occur, especially in preterm infants. Infections limited to the placenta and/or umbilical cord or to the skin respond well to minimal antifungal therapy and almost always have favorable outcomes. On the other hand, systemic dissemination of congenital candidiasis is a severe cause of early-onset sepsis, involving a high mortality rate (35\%).

Preterm infants are predisposed to Candida infections mainly due to the immaturity of their immune system. Congenital candidiasis is rare and must be distinguished from other conditions presenting with pustular lesions at birth, in order to avoid severe complications, which may have lifelong repercussions.

\section{Aim}

In this paper, we develop a meta-analysis of all previously reported cases of systemically disseminated congenital candidiasis in the English literature, regarding gestational age and weight at delivery, duration of membrane rupture, extent of infection and association with an intrauterine foreign body, in the attempt to picture a comprehensive clinical and morphological spectrum of this extremely rare disease.

This is an open-access article distributed under the terms of a Creative Commons Attribution-NonCommercial-ShareAlike 4.0 International Public License, which permits unrestricted use, adaptation, distribution and reproduction in any medium, non-commercially, provided the new creations are licensed under identical terms as the original work and the original work is properly cited. 


\section{a Methods}

Multiple PubMed surveys using various combinations of the following terms: "congenital", "intrauterine", "Candida", "candidiasis", "candidemia", "systemic", "invasive" and "disseminated" revealed a total of 43 cases published in English journals, as far back as year 1966, mainly as isolated case reports and short case series. Most search results included reports of perinatal nosocomial infections with Candida spp. or congenital cutaneous infections with Candida spp. showing no signs of systemic involvement. We also identified series of cases including congenital systemic candidiasis and congenital cutaneous candidiasis. Only cases with confirmed systemic infection have been included in this study. Systemic infection has been defined as having a positive blood, urine, and/or cerebrospinal fluid culture for Candida spp., or demonstration of Candida in histopathological (HP) or culture specimens obtained at autopsy.

\section{a Results}

Tables 1 and 2 summarize the main characteristics of the 44 infants with congenital systemic candidiasis identified in the English literature [1-40].

Table 1 - Clinical features of infants with systemic congenital candidiasis

\begin{tabular}{|c|c|c|c|c|c|c|c|}
\hline $\begin{array}{c}\text { Case } \\
\text { No. }\end{array}$ & Author(s), Country (year) [Reference No.] & $\begin{array}{c}\text { Fetal } \\
\text { gender }\end{array}$ & $\begin{array}{c}\text { GA } \\
\text { [weeks] }\end{array}$ & $\begin{array}{l}\text { BW } \\
\text { [g] }\end{array}$ & $\begin{array}{c}\text { Foreign } \\
\text { body }\end{array}$ & $\begin{array}{c}\text { ROM } \\
\text { [hours] }\end{array}$ & $\begin{array}{l}\text { Delivery } \\
\text { method }\end{array}$ \\
\hline 1. & Dvorak \& Gavaller, USA (1966) [2] & NA & 32 & 2736 & None & 0 & CS \\
\hline 2. & Albarracin et al., Canada (1967) [13] & $\mathrm{F}$ & 24 & 800 & None & $>48$ & SVD \\
\hline 3. & Aterman, Canada (1968) [24] & $\mathrm{F}$ & 22 & 440 & None & 0 & SVD \\
\hline 4. & Lopez \& Aterman, Canada (1968) [34] & $\mathrm{F}$ & 28 & 1219 & None & 0 & SVD \\
\hline 5. & Misenhimer \& Garcia-Bunuel, USA (1969) [35] - Case \#1 & $\mathrm{M}$ & 26 & 1070 & IUD & $24-48$ & SVD \\
\hline 6. & Misenhimer \& Garcia-Bunuel, USA (1969) [35] - Case \#2 & $\mathrm{F}$ & 24 & 800 & IUD & $<12$ & SVD \\
\hline 7. & Ho \& Aterman, Canada (1970) [36] & NA & 16 & 75 & IUD & $<12$ & SA \\
\hline 8. & Schirar et al., France (1974) [37] & $\mathrm{M}$ & 20 & 650 & Cerclage & 0 & SVD \\
\hline 9. & Brandsma et al., Netherlands (1975) [38] & NA & 20 & 360 & IUD & 0 & SA \\
\hline 10. & Levin et al., Israel (1978) [39] - Twin \#2 & $\mathrm{F}$ & 29 & 520 & None & $>48$ & SVD \\
\hline 11. & Buchanan et al., UK (1979) [3] & $\mathrm{F}$ & 25 & NA & IUD & 0 & SVD \\
\hline 12. & Johnson et al., USA (1981) [4] & $\mathrm{F}$ & 27 & 1080 & None & 0 & SVD \\
\hline 13. & Nagata et al., Japan (1981) [5] & $\mathrm{F}$ & 35 & 2530 & None & $>48$ & SVD \\
\hline 14. & Delprado et al., Australia (1982) [6] & $\mathrm{M}$ & 34 & 2275 & IUD & $12-24$ & CS \\
\hline 15. & Bittencourt et al., Brazil (1984) [7] & $\mathrm{M}$ & 19 & 110 & IUD & 0 & SA \\
\hline 16. & Mamlok et al., USA (1985) [8] & $\mathrm{F}$ & 36 & 2560 & None & $>48$ & SVD \\
\hline 17. & Smith et al., USA (1988) [9] & NA & 16 & 104 & IUD & $>48$ & IL \\
\hline 18. & Donders et al., Belgium (1991) [10] & $\mathrm{F}$ & 22 & 450 & IUD & $12-24$ & SVD \\
\hline 19. & Ng et al., Hong Kong (1994) [11] & $\mathrm{F}$ & 24 & 815 & Cerclage & 0 & SVD \\
\hline 20. & Barone \& Krilov, USA (1995) [12] & $\mathrm{F}$ & 39 & NA & None & 0 & CS \\
\hline 21. & Nichols et al., Australia (1995) [14] & M & 25 & 760 & IUD & 0 & SVD \\
\hline 22. & Roqué et al., USA (1999) [1] & $\mathrm{M}$ & 20 & 398 & IUD & $25-48$ & $\mathrm{IL}$ \\
\hline 23. & Waguespack-LaBiche et al., USA (1999) [15] & $\mathrm{M}$ & 25 & 520 & None & $>48$ & IL \\
\hline 24. & Arai et al., Japan (2002) [16] - Twin \#1 & $\mathrm{M}$ & 29 & 1118 & None & 0 & CS \\
\hline 25. & Aldana-Valenzuela et al., Mexico (2005) [17] & $\mathrm{F}$ & 39 & 2540 & None & 0 & CS \\
\hline 26. & Krallis et al., Greece (2006) [18] - Twin \#1 & $\mathrm{F}$ & 26 & 425 & None & NA & SVD \\
\hline 27. & Krallis et al., Greece (2006) [18] - Twin \#2 & M & 26 & 535 & None & NA & SVD \\
\hline & Baradkar et al., India (2007) [19] & $\mathrm{M}$ & 26 & 1800 & None & NA & NA \\
\hline & Carmo et al., Australia (2007) [20] - Twin \#1 & $\mathrm{F}$ & 32 & 1694 & None & $12-24$ & CS \\
\hline & Meizoso et al., Spain (2008) [21] & $\mathrm{F}$ & 28 & 500 & IUD & 0 & $\mathrm{IL}$ \\
\hline & Wang et al., Taiwan (2008) [22] - Case \#1 & $\mathrm{F}$ & 34 & 2012 & None & NA & CS \\
\hline & Wang et al., Taiwan (2008) [22] - Case \#2 & $\mathrm{M}$ & 38 & 3390 & None & NA & CS \\
\hline & Haase et al., Germany (2009) [23] & $\mathrm{F}$ & 33 & 1530 & None & NA & SVD \\
\hline & Tiraboschi et al., Argentina (2010) [25] & $\mathrm{F}$ & 27 & 1020 & None & $<12$ & CS \\
\hline & Nouri-Merchoui et al., Tunisia (2011) [26] & $\mathrm{F}$ & 35 & NA & None & NA & SVD \\
\hline & Li et al., Taiwan (2012) [27] & $\mathrm{F}$ & 26 & 770 & None & $>48$ & SVD \\
\hline 37. & Pineda et al., USA (2012) [28] - Twin \#1 & M & 29 & 1440 & None & $12-24$ & CS \\
\hline & Pineda et al., USA (2012) [28] - Twin \#2 & $\mathrm{M}$ & 29 & 1370 & None & $12-24$ & CS \\
\hline 39. & Siriratsivawong et al., USA (2014) [29] & M & 37 & NA & None & $<12$ & SVD \\
\hline 40. & Chen et al., Taiwan (2015) [31] - Twin \#1 & $\mathrm{M}$ & 30 & 1664 & None & $<12$ & SVD \\
\hline 41. & Chen et al., Taiwan (2015) [31] - Twin \#2 & $\mathrm{F}$ & 30 & 1488 & None & $<12$ & SVD \\
\hline 42. & Oberhauser et al., Switzerland (2017) [32] & M & 25 & 920 & None & 0 & CS \\
\hline 43. & Lee et al., Malaysia (2017) [33] - Twin \#1 & $\mathrm{F}$ & 29 & 1650 & None & 0 & SVD \\
\hline 44. & Georgescu et al., Romania (2019) [40] - Our case & $\mathrm{M}$ & 30 & 1100 & None & $<12$ & SVD \\
\hline
\end{tabular}

BW: Birth weight; CS: Caesarean section; F: Female; GA: Gestational age; IL: Induced labor; IUD: Intrauterine device; M: Male; NA: Not available; ROM: Rupture of membranes; SA: Spontaneous abortion; SVD: Spontaneous vaginal delivery. 
Table 2 - Clinical features of infants with congenital systemic candidiasis

\begin{tabular}{|c|c|c|c|c|c|}
\hline $\begin{array}{l}\text { Case } \\
\text { No. }\end{array}$ & $\begin{array}{l}\text { Maternal history of } \\
\text { vaginal discharge }\end{array}$ & $\begin{array}{l}\text { Maternal therapy } \\
\text { during pregnancy }\end{array}$ & $\begin{array}{l}\text { Blood, urine or } \\
\text { tissue culture } \\
\text { specimens }\end{array}$ & $\begin{array}{l}\text { Organ involvement confirmed } \\
\text { by culture or histopathological } \\
\text { examination (except blood/urine) }\end{array}$ & $\begin{array}{l}\text { Fetal outcome } \\
\text { (survival time) }\end{array}$ \\
\hline 1. & NA & NA & C. albicans & $\mathrm{L}, \mathrm{GI}, \mathrm{K}$ & Fatal (34 hours) \\
\hline 2. & NA & NA & C. albicans & S, L, GI & Fatal (NA) \\
\hline 3. & No & No & C. albicans & UC, L, GI & Fatal (six hours) \\
\hline 4. & No & No & C. albicans & $\mathrm{UC}, \mathrm{GI}$ & Fatal (13 hours) \\
\hline 5. & Yes & No & NA & FM, L & Fatal (29 hours) \\
\hline 6. & Yes & No & C. albicans & $\mathrm{L}, \mathrm{GI}$ & Fatal (114 hours) \\
\hline 7. & No & No & NA & FM, L, GI & Abortion \\
\hline 8. & Yes & NA & C. albicans & UC, FM, P, L, GI & Stillborn \\
\hline 9. & No & No & C. albicans & UC, FM, P, S, L, GI, LN & Abortion \\
\hline 10. & No & $A B$ & C. albicans & $\mathrm{P}, \mathrm{B}$ & Stillborn \\
\hline 11. & Yes & Yes (NA) & NA & UC, S, L & Stillborn \\
\hline 12. & Yes & No & C. albicans & $P, S, L, B$ & Fatal (14 days) \\
\hline 13. & Yes & NA & C. albicans & $P, L$ & Fatal (one hour) \\
\hline 14. & Yes & Yes (NA) & C. albicans & UC, FM, P, S, L, LIV & Fatal (90 minutes) \\
\hline 15. & Yes & AF & NA & UC, FM, P, S, L, GI & Abortion \\
\hline 16. & Yes & $A B$ & C. albicans & UC, FM, P, L & Fatal (14 hours) \\
\hline 17. & No & No & NA & L, GI & Abortion \\
\hline 18. & No & No & C. albicans & UC, FM, P, L & Stillborn \\
\hline 19. & No & CORT & C. albicans & $\mathrm{L}, \mathrm{GI}$ & Survival \\
\hline 20. & No & CORT & C. albicans & S, B & Survival \\
\hline 21. & No & No & C. tropicalis & FM, P, L & Stillborn \\
\hline 22. & No & No & C. albicans & FM, P, B, LIV & Stillborn \\
\hline 23. & No & $A B$ & $\begin{array}{l}\text { C. parapsilosis + } \\
\text { C. albicans }\end{array}$ & S, L, GI & Survival \\
\hline 24. & No & No & C. glabrata & $\mathrm{S}, \mathrm{L}, \mathrm{GI}$ & Survival \\
\hline 25. & Yes & Insulin & C. albicans & $S, L$ & Survival \\
\hline 26. & No & CORT & C. parapsilosis & L, GI & Fatal (72 hours) \\
\hline 27. & No & CORT & C. albicans & $\mathrm{L}, \mathrm{GI}$ & Fatal (22 hours) \\
\hline 28. & NA & NA & C. albicans & $\mathrm{B}$ & Survival \\
\hline 29. & No & $A B$ & C. albicans & $\mathrm{P}, \mathrm{L}, \mathrm{LIV}$ & Fatal (22 hours) \\
\hline 30. & Yes & AF & C. albicans & UC, FM, L, GI & Stillborn \\
\hline 31. & Yes & NA & C. albicans & $\mathrm{S}, \mathrm{L}$ & Survival \\
\hline 32. & No & No & C. albicans & $S$ & Survival \\
\hline 33. & No & No & C. albicans & $\mathrm{S}$ & Survival \\
\hline 34. & No & No & C. albicans & UC, $\mathrm{P}$ & Survival \\
\hline 35. & No & $A B$ & C. albicans & $S$ & Survival \\
\hline 36. & No & No & C. albicans & $\mathrm{S}, \mathrm{H}, \mathrm{K}$ & Fatal (128 days) \\
\hline 37. & No & $A B$ & C. kefyr & UC, FM, P & Survival \\
\hline 38. & No & $A B$ & C. kefyr & UC, FM, P & Survival \\
\hline 39. & No & $A B$ & C. albicans & $\mathrm{UC}, \mathrm{P}, \mathrm{S}$ & Survival \\
\hline 40. & No & No & C. albicans & $\mathrm{P}, \mathrm{S}, \mathrm{L}$ & Fatal (81 hours) \\
\hline 41. & No & No & C. albicans & $\mathrm{P}, \mathrm{K}$ & Survival \\
\hline 42. & No & $A B+C O R T$ & C. albicans & $\mathrm{S}, \mathrm{K}$ & Survival \\
\hline 43. & Yes & No & C. albicans & $\mathrm{L}$ & Fatal (32 hours) \\
\hline 44. & No & No & C. albicans & L, GI, K, LIV, SPL, B & Fatal (76 hours) \\
\hline
\end{tabular}

AB: Antibiotics; AF: Antifungal; B: Brain; CORT: Corticosteroids; FM: Fetal membranes; GI: Gastrointestinal tract; H: Heart; K: Kidney; L: Lungs; LIV: Liver; LN: Lymph node; NA: Not available; P: Placenta; S: Skin; SPL: Spleen; UC: Umbilical cord.

Seven authors reported twin pregnancies $[16,18,20$, $28,31,33,39]$. In three of these cases, both twins suffered systemic infection with Candida spp. [18, 28, 31]. Among the remaining four cases, only one twin suffered systemic infection, while the other twin was either unaffected or featured only cutaneous manifestations [16, 20, 33, 39]. As already mentioned, unaffected twins or twins with cutaneous rash and no systemic involvement have been excluded from this study. Surprisingly, all cases in which both twins were equally affected were dichorionic diamniotic pregnancies, while cases where only one twin was affected were mainly monochorionic diamniotic pregnancies.

At least 14 (34.15\%) mothers had an intrauterine foreign body in place, either in the form of cervical cerclage or an intrauterine device (IUD). The presence of an intrauterine body was associated with congenital systemic candidiasis in babies weighing less than $1000 \mathrm{~g}$ (12 out of 14), suggesting that the foreign body could predispose the infant to invasive candidiasis and 
subsequent preterm birth during the first two trimesters of gestation.

There were five (11.36\%) miscarriages, 35 (79.55\%) preterm deliveries and four $(9.09 \%)$ full-term deliveries. Most women entered spontaneous labor (54.55\%). There were three $(6.82 \%)$ spontaneous abortions, 12 (27.27\%) pregnancies delivered by Caesarean section and four $(9.09 \%)$ cases were labor was induced therapeutically. There were 17 (38.64\%) live births with subsequent fatal outcome, $11(25 \%)$ cases of abortion/stillbirth and 16 $(36.36 \%)$ cases in which the newborn survived. In fatal cases, survival ranged from 90 minutes to 128 days. All pregnancies with a total duration of ruptured membranes of more than 48 hours were fatal $(n=7)$, but so were most of the pregnancies with intact membranes (11 out of 16). However, this information was not available in seven cases.

Gestational age ranged between 16 and 39 weeks, with an average of 27.86 weeks and a standard deviation of 5.84. Birth weight ranged between $75 \mathrm{~g}$ and $3390 \mathrm{~g}$, with an average of $1180.95 \mathrm{~g}$ and a standard deviation of 809.87 .

In at least $14(34.15 \%)$ cases, a maternal history of vaginal discharge has been confirmed and 13 of them had fatal outcome. During pregnancy, nine (21.95\%) patients received antibiotics, five $(12.19 \%)$ patients received corticosteroids and only two $(4.88 \%)$ patients received antifungal therapy, but fetal outcome did not appear to be meaningfully impacted by any of those medications.

Based on the information in our meta-analysis, typical sites of infection were those in direct contact with the amniotic fluid: umbilical cord, fetal membranes, placental surface, fetal skin, lungs, and gastrointestinal tract. Among the 44 cases identified in the scientific literature, there was only one case with involvement of the fetal heart and one case with involvement of the lymph nodes. Georgescu et al. (2019) reported the only case with involvement of the fetal spleen [40]. Organ involvement confirmed by culture and/or HP examination is summarized in Figure 1.

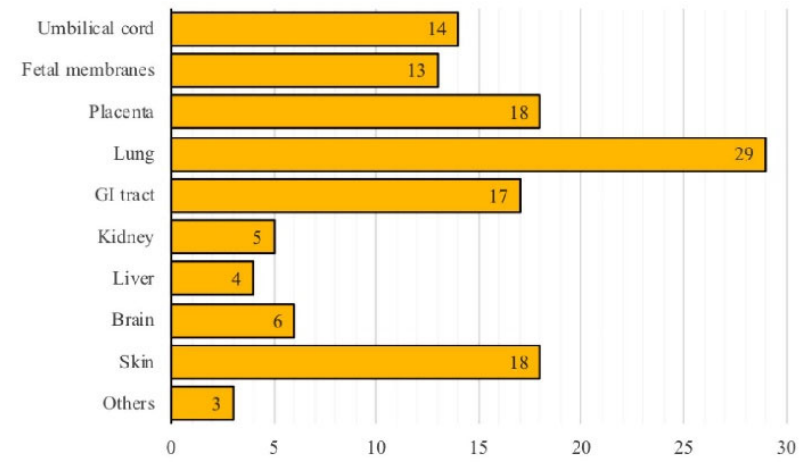

Figure 1 - Organ involvement confirmed by culture and/or histopathological examination. GI: Gastrointestinal.

\section{口 Discussions}

Congenital systemic candidiasis is an extremely rare disease and as more cases are recognized, additional and important evidence can be gained for a better understanding of this enigmatic clinical entity. The first case of Candida infection of the uterine contents during pregnancy was reported by Benirschke \& Raphael, in 1958 [41]. They reported the case of a 36-year-old gravida II para I who gave birth to an anencephalic female infant with $C$. albicans chorioamnionitis confirmed by positive cultures from the fetal membranes and placenta. This is also the first and only association reported in the scientific literature between anencephaly and congenital candidiasis. However, no autopsy was performed and no information about fetal fluid or organ involvement is available. The first biologically confirmed congenital systemic infection with Candida spp. was published in New England Journal of Medicine by Dvorak \& Gavaller, in 1966 [2], and was followed by a plethora of case reports and case series, including twin and singleton pregnancies (Tables 1 and 2). After a comprehensive review of all these reports, we have summarized in this paper the etiopathogenesis, risk factors, clinical presentation, methods of diagnosis, possible differential diagnoses, as well as treatment and outcome of congenital systemic candidiasis.

\section{Etiopathogenesis}

C. albicans is a common inhabitant and frequent pathogen of the female genital tract, especially during pregnancy [42]. In our meta-analysis, C. albicans was isolated from cultures in 34 cases, but as microbiological techniques improved, other Candida strains were identified as pathogens. Nichols et al. reported a case of $C$. tropicalis disseminated chorioamnionitis [14]. Krallis et al. [18] and Waguespack-LaBiche et al. [15] reported infections with $C$. parapsilosis. Arai et al. [16] reported a case of dichorionic diamniotic twin pregnancy in which one of the twins presented congenital infection with C. glabrata. Pineda et al. [28] reported a case of dichorionic diamniotic twin pregnancy in which both infants suffered congenital infection with C. kefyr.

Two different routes of intrauterine infection have been postulated [43]. If present in the maternal circulation, fungal microorganisms could reach the fetal circulation through the placenta. This route invariably results in a widespread pattern of visceral involvement, with prominent lesions mainly affecting the liver [43]. The alternate and more probable scenario is that microorganisms from the maternal genital tract might penetrate ruptured or intact fetal membranes and infect the amniotic fluid. This vaginal ascending route results in an inflammatory process primarily affecting the amniotic fluid and amniotic surface of the placenta and umbilical cord. The fetus develops cutaneous manifestations and is secondarily infected by swallowing and aspirating infected amniotic material. The most severely affected are the gastrointestinal and respiratory systems with subsequent systemic dissemination and multiorgan failure [43, 44]. Most importantly, Candida can penetrate intact fetal membranes and intrauterine infection can develop in the absence of symptomatic vaginal candidiasis [45].

Multiple studies conclude that the magnitude of secondary spread from the amnion varies considerably, based on the virulence of the microorganism, degree of contamination and fetal immune response [8, 37]. Premature, low birth weight infants with diminished fetal response have increased risk of dissemination and 
death [46, 47]. Maternal risk factors include antibiotic therapy during labor, symptomatic vulvovaginal candidiasis, the use of intrauterine contraceptive devices and presence of cervical sutures during pregnancy $[6,35,48]$. However, none of these maternal risk factors can be used as a reliable predictor for the severity of congenital candidiasis [44].

Spreading of the infection to the lungs, pharynx, and the colonization of the digestive tract, as reported in our case, occurred due to inhaling and swallowing infected amnionic fluid. Hematogenous spread to the liver, kidney, spleen, and brain was probably favored by the immature immune system of the preterm infant.

\section{Risk factors}

Congenital candidiasis appears in the setting of Candida vulvovaginitis, which affects approximately $25 \%$ of all pregnant women $[49,50]$. Although frequently present in the vagina, less than $1 \%$ of placentas are confirmed with Candida on the fetal surface [51]. Among these cases, congenital cutaneous infection of the fetus is rare and systemic involvement is exceptional. The reason why some infants born from women with vulvovaginitis develop congenital candidiasis, while others do not, remains unknown. Chen et al. published the first molecular evidence of congenital systemic candidiasis associated with maternal Candida vaginitis [30]. They encountered a premature infant with congenital invasive candidiasis in whom isolates of C. albicans from the blood and oral cavity of the infant as well as vagina of the mother were available for genotyping analysis. Both isolates from the infant and the mother shared an identical pulsed-field gel electrophoresis pattern, while the three control strains belonged to three different genotypes, distinct from the genotype of the case infant. Similar results using the same method have been subsequently reported by Tiraboschi et al., in 2010 [25].

The presence of a foreign body, such as an IUD or cervical sutures, appear to be the most important risk factors associated with congenital systemic candidiasis and early preterm birth. Extensive instrumentation in the delivery room and invasive procedures, such as placement of an indwelling catheter in the neonatal period or an altered immune response, particularly neutrophil or macrophage function may increase the risk for subsequent development of systemic disease.

Diagnostic amniocentesis has preceded and may trigger the development of congenital cutaneous candidiasis [52]. Maternal age, parity, diabetes, nutrition, urinary tract infections, prolonged labor and tocolytic therapy do not appear to be risk factors for congenital candidiasis [5359]. However, congenital candidiasis may precipitate premature rupture of membranes and preterm delivery. Although maternal diabetes is not considered a risk factor for congenital candidiasis [53], this is not a proven fact and further studies are needed before this condition is discarded.

Chen et al. described that first infants from premature twin pregnancies have higher risk of invasive candidiasis compared to the other twin, because they are the first to be affected by ascending infection, while the second twins are usually infected during delivery [31]. Thus, second twins are generally less severely affected than first twins, as observed in four out of the seven twin case reports we identified.

Barone \& Krilov reported a case of Candida meningitis in a full-term infant with congenital cutaneous candidiasis from a mother with short-term prenatal Prednisone exposure [12]. Corticosteroids, which are a known risk factor for Candida infection, decrease neutrophil function and may have depressed the infant's immune function, allowing Candida dissemination.

\section{Clinical presentation}

Congenital candidiasis has a plethora of clinical features, ranging from a diffuse erythematous skin eruption with or without vesicles and pustules to systemic disease, with or without skin involvement, in which the lung and gastrointestinal tract are most frequently affected [60].

Skin lesions in congenital candidiasis typically present on the first day of life and sometimes can be delayed up to six days. The typical rash consists of a generalized eruption of $2 \mathrm{~mm}$ to $4 \mathrm{~mm}$ erythematous macules, papules and/or pustules. Carmo et al. [20] reported a case of congenital candidiasis without rash, presenting with overwhelming septic shock and neutropenia. They encountered a twin pregnancy in which the presenting twin succumbed due to candidemia with no signs or symptoms to suggest $C$. albicans infection. The other twin eventually developed florid pustulo-vesicular and markedly pruritic truncal rash, with diffuse erythroderma, but made a complete recovery under Amphotericin B therapy.

The most common manifestation of congenital systemic candidiasis is sepsis with respiratory distress. Once the symptoms are evident, the clinical course is so fulminant that even prompt initiation of antifungal therapy is rarely lifesaving [15, 20, 26].

Candidal meningitis is a frequent manifestation of congenital candidiasis, with limited information available on long-term neurodevelopment. The infants present cerebrospinal fluid alterations similar to those observed in other infections, such as tuberculosis, cryptococcosis and histoplasmosis [61-63]. In our meta-analysis, we identified four cases of Candida meningitis, two of which had favorable outcome $[12,19]$.

\section{Diagnosis}

Definitive diagnosis of invasive congenital candidiasis can be confirmed by fungal culture from a sterile body fluid from the newborn (such as blood, urine or cerebrospinal fluid, etc.) and/or microscopic demonstration of spores and pseudohyphae of $C$. albicans [22, 64]. Immunological evaluation generally does not reveal any specific defect and has no diagnostic significance.

The lesions in the umbilical cord are frequently associated with other lesions in the fetal adnexa. However, nowhere can the characteristic pathology be seen as clearly and as easily as in the umbilical cord, which should always be examined most carefully. Gross examination of the umbilical cord should reveal small, round, whiteyellow lesions measuring $0.5-2 \mathrm{~mm}$, clustered along the surface of the cord, sometimes penetrating deeply within the Wharton's jelly. The extraplacental membranes may feature diffuse yellow exudate on the fetal surface. Infrequently, the chorionic surface, intervillous space and sometimes even the chorionic villi may be affected. 
Yeasts and pseudohyphae can be identified in routine Hematoxylin-Eosin (HE) staining but are best visualized using Periodic Acid-Schiff (PAS) or Gömöri Methenamine Silver stainings. In the umbilical cord, the inflammation usually has a wedge shape, with the wide base towards the surface of the cord and is composed of neutrophils, lymphocytes and histiocytes. Cellularity and microorganisms tend to lower in density towards the center of the umbilical cord and rarely extend to the umbilical vessels [65].

\section{Differential diagnosis}

Based on the clinical presentation, the differential diagnosis of congenital candidiasis can be very extensive. Systemic infection may or may not be associated with cutaneous involvement. When mucocutaneous lesions are present, congenital candidiasis should be included in the differential diagnosis of other neonatal generalized maculopapular or pustular skin eruptions, such as: staphylococcal pustulosis, Listeria monocytogenes infection, impetigo, chickenpox, Herpes simplex virus infection, syphilis, erythema toxicum neonatorum, milia, Ritter's disease, Leiner's disease, epidermolysis bullosa and Langerhans cell histiocytosis [66].

Infants lacking mucocutaneous manifestations usually present with fever and severe respiratory distress, raising the possibility for neonatal bacterial infection and septicemia.

\section{Treatment and outcome}

In full-term infants, congenital cutaneous candidiasis almost invariably follows a self-limited, benign course, despite the presence of chorioamnionitis and funisitis. On the other hand, preterm infants with low birth weight have the highest risk for development of systemic disease. They may be stillborn or may present early in neonatal life with in utero acquired infection. Those with burnlike dermatitis are at particularly high risk for systemic infection and death [67-70]. The overall mortality of untreated systemic candidiasis ranges between $39 \%$ and $94 \%$. Therefore, early diagnosis and treatment are crucial.

Prompt initiation of antifungal therapy appears to be the most important factor associated with survival in systemic infection [68-70]. Amphotericin B is the first-line agent for treatment of congenital systemic candidiasis [71]. Unfortunately, some patients do not show improvement and evolve to persistent candidemia and further clinical deterioration. In these cases, replacing Amphotericin B with Caspofungin, has been reported highly effective in controlling neonatal candidemia refractory to Amphotericin B therapy and a possible salvage therapy. Additional benefit may be provided by introduction of 5-Flucytosine. Use of Fluconazole may be considered when toxicity to Amphotericin $\mathrm{B}$ is prohibitive and the organism is susceptible, although data to support its use for treatment of systemic candidal infection in preterm infants are lacking.

Haase et al. detailed the clinical findings and successful treatment of $C$. albicans fungemia in a preterm infant with congenital ichthyosis (Harlequin baby) [23]. The infant developed systemic candidiasis refractory to liposomal Amphotericin B and was treated with echinocandin Caspofungin, which led to prompt eradication of C. albicans fungemia without serious side effects. Oberhauser et al. also reported positive results in treating refractory candidemia with echinocandin Micafungin [32].

Congenital cutaneous candidiasis should be considered an invasive Candida infection, especially in preterm infants. We believe that infants with suspected congenital candidiasis should be considered as candidates for systemic antifungal therapy in any of the following cases: $(i)$ evidence of respiratory distress or other laboratory or clinical signs of sepsis in the immediate neonatal period; (ii) birth weight less than $1500 \mathrm{~g}$; (iii) treatment with broad-spectrum antibiotics; (iv) extensive instrumentation during delivery or invasive procedures in the neonatal period; $(v)$ positive systemic cultures; and ( $v i)$ evidence of an altered immune response.

We also believe that in cases with positive amniotic fluid Candida cultures, early aggressive therapy should be started before birth. Shalev et al. reported a case of intra-amniotic infection with $C$. albicans successfully treated in utero with antifungal drugs which had favorable outcome [72].

\section{ㅁ Conclusions}

Invasive congenital candidiasis must be taken into consideration in newborns with unaccountable respiratory distress syndrome, fever, and poor response to antibiotic treatment, especially in the presence of maternal risk factors, such as history of vaginal discharge or presence of an intrauterine foreign body during pregnancy. In these cases, antifungal therapy should be initiated immediately, even in the absence of cutaneous involvement or placental culture/pathology results. Our meta-analysis revealed that the most reliable indicators for predicting disease extent and outcome were gestational age, fetal birth weight and symptomatology at birth. Infants with very early onset of severe respiratory symptoms died with histological evidence of Candida pneumonia. Cutaneous involvement, while usually indicative of localized disease, was associated with fatal outcome when one of these risk factors was also present.

\section{Conflict of interests}

The authors declare that they have no conflict of interests.

\section{References}

[1] Roqué $H$, Abdelhak $Y$, Young BK. Intra amniotic candidiasis. Case report and meta-analysis of 54 cases. J Perinat Med, 1999, 27(4):253-262. https://doi.org/10.1515/JPM.1999.036 PMID: 10560076

[2] Dvorak AM, Gavaller B. Congenital systemic candidiasis. Report of a case. N Engl J Med, 1966, 274(10):540-543. https:// doi.org/10.1056/NEJM196603102741003 PMID: 5907489

[3] Buchanan R, Sworn MJ, Noble AD. Abortion associated with intrauterine infection by Candida albicans. Case report. $\mathrm{Br} \mathrm{J}$ Obstet Gynaecol, 1979, 86(9):741-744. https://doi.org/10.11 11/j.1471-0528.1979.tb11278.x PMID: 497146

[4] Johnson DE, Thompson TR, Ferrieri P. Congenital candidiasis. Am J Dis Child, 1981, 135(3):273-275. https://doi.org/10.10 01/archpedi.1981.02130270065023 PMID: 7211787

[5] Nagata K, Nakamura $Y$, Hosokawa $Y$, Nakashima T, Nagasue N, Kabashima K, Hidaka S. Intrauterine Candida infection in premature baby. Acta Pathol Jpn, 1981, 31(4): 695-699. https://doi.org/10.1111/j.1440-1827.1981.tb02765.x PMID: 7282369 
[6] Delprado WJ, Baird PJ, Russell P. Placental candidiasis: report of three cases with a review of the literature. Pathology, 1982, 14(2):191-195. https://doi.org/10.3109/003130282090 61293 PMID: 7099725

[7] Bittencourt AL, dos Santos WLC, de Oliveira CH. Placental and fetal candidiasis. Mycopathologia, 1984, 87(3):181-187. https://doi.org/10.1007/BF00436906

[8] Mamlok RJ, Richardson CJ, Mamlok V, Nichols MM Goldblum RM. A case of intrauterine pulmonary candidiasis. Pediatr Infect Dis, 1985, 4(6):692-693. https://doi.org/10.10 97/00006454-198511000-00021 PMID: 4080587

[9] Smith CV, Horenstein J, Platt LD. Intraamniotic infection with Candida albicans associated with a retained intrauterine contraceptive device: a case report. Am J Obstet Gynecol, 1988, 159(1):123-124. https://doi.org/10.1016/0002-9378(88) 90505-4 PMID: 3394730

[10] Donders GG, Moerman P, Caudron J, Van Assche FA. Intrauterine Candida infection: a report of four infected fetuses from two mothers. Eur J Obstet Gynecol Reprod Biol, 1991, 38(3):233-238. https://doi.org/10.1016/0028-2243(91)90298-y PMID: 2007451

[11] Ng PC, Siu YK, Lewindon PJ, Wong W, Cheung KL, Dawkins R. Congenital Candida pneumonia in a preterm infant. $\mathrm{J}$ Paediatr Child Health, 1994, 30(6):552-554. https://doi.org/10.1111/ j.1440-1754.1994.tb00734.x PMID: 7865275

[12] Barone SR, Krilov LR. Neonatal candidal meningitis in a full-term infant with congenital cutaneous candidiasis. Clin Pediatr (Phila), 1995, 34(4):217-219. https://doi.org/10.1177/ 000992289503400408 PMID: 7789016

13] Albarracin NS Jr, Patterson WS, Haust MD. Candida albicans infection of the placenta and fetus. Report of a case. Obstet Gynecol, 1967, 30(6):838-841. PMID: 6061835

[14] Nichols A, Khong TY, Crowther CA. Candida tropicalis chorioamnionitis. Am J Obstet Gynecol, 1995, 172(3):1045-1047. https://doi.org/10.1016/0002-9378(95)90044-6 PMID: 7892848

[15] Waguespack-LaBiche J, Chen SH, Yen A. Disseminated congenital candidiasis in a premature infant. Arch Dermatol, 1999, 135(5):510-512. https://doi.org/10.1001/archderm.135 5.510 PMID: 10328188

[16] Arai H, Goto R, Matsuda T, Saito S, Hirano H, Sanada H, Sato A, Takada G. Case of congenital infection with Candida glabrata in one infant in a set of twins. Pediatr Int, 2002 44(4):449-450. https://doi.org/10.1046/j.1442-200x.2002.015 65.x PMID: 12139576

[17] Aldana-Valenzuela C, Morales-Marquec M, CastellanosMartínez J, DeAnda-Gómez M. Congenital candidiasis: a rare and unpredictable disease. J Perinatol, 2005, 25(10):680 682. https://doi.org/10.1038/sj.jp.7211379 PMID: 16193080

[18] Krallis N, Tzioras S, Giapros V, Leveidiotou S, Paschopoulos M Stefanou D, Andronikou S. Congenital candidiasis caused by different Candida species in a dizygotic pregnancy. Pediatr Infect Dis J, 2006, 25(10):958-959. https://doi.org/10.1097/ 01.inf.0000235683.57619.05 PMID: 17006301

[19] Baradkar VP, Taklikar SM. Meningitis caused by Candida albicans in a premature neonate. J Pediatr Neurosci, 2007, 2(2):90-91. https://doi.org/10.4103/1817-1745.36773

[20] Carmo KB, Evans N, Isaacs D. Congenital candidiasis presenting as septic shock without rash. Arch Dis Child, 2007, 92(7):627-628. https://doi.org/10.1136/adc.2007.115865 PMID: 17234655 PMCID: PMC2083776

[21] Meizoso T, Rivera T, Fernández-Aceñero MJ, Mestre MJ, Garrido M, Garaulet C. Intrauterine candidiasis: report of four cases. Arch Gynecol Obstet, 2008, 278(2):173-176. https:// doi.org/10.1007/s00404-007-0554-7 PMID: 18214512

[22] Wang SM, Hsu CH, Chang JH. Congenital candidiasis. Pediatr Neonatol, 2008, 49(3):94-96. https://doi.org/10.1016/S1875 -9572(08)60020-0

[23] Haase R, Kreft B, Foell J, Kekulé AS, Merkel N. Successful treatment of Candida albicans septicemia in a preterm infant with severe congenital ichthyosis (Harlequin baby). Pediatr Dermatol, 2009, 26(5):575-578. https://doi.org/10.1111/j.15 25-1470.2009.00989.x PMID: 19840314

[24] Aterman K. Pathology of Candida infection of the umbilical cord. Am J Clin Pathol, 1968, 49(6):798-804. https://doi.org/ 10.1093/ajcp/49.6.798 PMID: 5654507

[25] Tiraboschi ICN, Niveyro C, Mandarano AM, Messer SA, Bogdanowicz E, Kurlat I, Lasala MB. Congenital candidiasis: confirmation of mother-neonate transmission using molecular analysis techniques. Med Mycol, 2010, 48(1):177-181. https:// doi.org/10.3109/13693780902824962 PMID: 19306215
[26] Nouri-Merchaoui S, Mahdhaoui N, Fekih M, Adouani M, Zakhama R, Methlouthi J, Ghith A, Seboui H. [Systemic congenital candidiasis, a rare condition in neonates: case report in a premature infant]. Arch Pediatr, 2011, 18(3):303-307. https://doi.org/10.1016/j.arcped.2010.12.017 PMID: 21292457

[27] Li MJ, Hsueh PR, Lu CY, Chou HC, Lee PI, Chang LY, Huang LM. Disseminated candidemia refractory to caspofungin therapy in an infant with extremely low birth weight. J Formos Med Assoc, 2012, 111(1):46-50. https://doi.org/10.1016/j.jfma. 2012.01.005 PMID: 22333013

[28] Pineda C, Kaushik A, Kest H, Wickes B, Zauk A. Maternal sepsis, chorioamnionitis, and congenital Candida kefyr infection in premature twins. Pediatr Infect Dis J, 2012, 31(3):320-322. https://doi.org/10.1097/INF.0b013e31823eee1a PMID: 22146738

[29] Siriratsivawong R, Pavlis M, Hymes SR, Mintzer JP. Congenital candidiasis: an uncommon skin eruption presenting at birth. Cutis, 2014, 93(5):229-232. PMID: 24897134

[30] Chen CJ, Weng YH, Su LH, Huang YC. Molecular evidence of congenital candidiasis associated with maternal candidal vaginitis. Pediatr Infect Dis J, 2006, 25(7):655-656. https:// doi.org/10.1097/01.inf.0000220233.00827.36 PMID: 16804443

[31] Chen WY, Chen SJ, Tsai SF, Tsao PC, Tang RB, Soong WJ. Congenital systemic fungus infection in twin prematurity - a case report and literature review. AJP Rep, 2015, 5(1):e46e50. https://doi.org/10.1055/s-0035-1548730 PMID: 26199798 PMCID: PMC4502635

[32] Oberhauser S, Böhm S, Niederer A, Rogdo B. Congenital cutaneous candidiasis and candidemia in a preterm infant: a case report. Case Rep Clin Pathol, 2017, 4(1):68-70. https:// doi.org/10.5430/crcp.v4n1p68

[33] Lee WQ, Teng LY, Pauline Choo PL, Tan KK. Congenital candidiasis: a rare and detrimental disease. Open J Pediatr Neonatal Care, 2017, 2(2):46-50. https://www.scireslit.com/ Pediatrics/OJPNC-ID20.pdf

[34] Lopez E, Aterman K. Intra-uterine infection by Candida. Am J Dis Child, 1968, 115(6):663-670. https://doi.org/10.1001/arch pedi.1968.02100010665005 PMID: 5654515

[35] Misenhimer HR, Garcia-Bunuel R. Failure of intrauterine contraceptive device and fungal infection in the fetus. Obstet Gynecol, 1969, 34(3):368-372. PMID: 5805536

[36] Ho CY, Aterman K. Infection of the fetus by Candida in a spontaneous abortion. Am J Obstet Gynecol, 1970, 106(5):705710. https://doi.org/10.1016/ 0002-9378(70)90394-7 PMID: 5413993

[37] Schirar A, Rendu C, Vielh JP, Gautray JP. Congenital mycosis (Candida albicans). Biol Neonate, 1974, 24(5-6):273-288. https://doi.org/10.1159/000240658

[38] Brandsma MAC, Braaksma JT, van der Harten JJ. Immature delivery after intrauterine Candida albicans infection. Eur $\mathrm{J}$ Obstet Gynecol Reprod Biol, 1975, 5(6):331-335. https:// doi.org/10.1016/0028-2243(75)90062-3 PMID: 1053526

[39] Levin S, Zaidel L, Bernstein D. Intrauterine infection of fetal brain by Candida. Am J Obstet Gynecol, 1978, 130(5):597599. https://doi.org/10.1016/0002-9378(78)90092-3 PMID: 629322

[40] Georgescu TA, Lisievici AC, Barbu S, Dumitru VA, Bohiltea R, Costache M, Sajin M. PS-16-015: Neonatal mortality due to congenital candidiasis in low birth weight infants: a 5-year retrospective study from an Emergency Unit in Romania. Abstracts of the $31^{\text {st }}$ European Congress of Pathology. Virchows Arch, 2019, 475(Suppl 1):S159. https://doi.org/10. 1007/s00428-019-02631-8 PMID: 31440833 PMCID: PMC 7103147

[41] Benirschke K, Raphael SI. Candida albicans infection of the amniotic sac. Am J Obstet Gynecol, 1958, 75(1):200-202. https://doi.org/10.1016/0002-9378(58)90572-6 PMID: 13487703

[42] Ruiz Velasco V, Rosas Arceo J. Prophylactic clotrimazole treatment to prevent mycoses contamination of the newborn. Int J Gynaecol Obstet, 1978, 16(1):70-71. https://doi.org/10. 1002/j.1879-3479.1978.tb00398.x PMID: 32096

[43] Blanc WA. Pathways of fetal and early neonatal infection. J Pediatr, 1961, 59(4):473-496. https://doi.org/10.1016/s00223476(61)80232-1 PMID: 13869795

[44] Jin Y, Endo A, Shimada M, Minato M, Takada M, Takahashi S, Harada K. Congenital systemic candidiasis. Pediatr Infect Dis J, 1995, 14(9):818-819. https://doi.org/10.1097/00006454-199 509000-00023 PMID: 8559641 
[45] Baley JE. Neonatal candidiasis: the current challenge. Clin Perinatol, 1991, 18(2):263-280. https://doi.org/10.1016/s00 95-5108(18)30523-2 PMID: 1879108

[46] Turcan N, Bohiltea RE, lonita-Radu F, Furtunescu F, Navolan D, Berceanu C, Nemescu D, Cirstoiu MM. Unfavorable influence of prematurity on the neonatal prognostic of small for gestational age fetuses. Exp Ther Med, 2020, 20(3):24152422. https://doi.org/10.3892/etm.2020.8744 PMID: 32765726 PMCID: PMC7401915

[47] Bohîlţea R, Furtunescu F, Turcan N, Navolan D, Ducu I, Cîrstoiu M. Prematurity and intrauterine growth restriction: comparative analysis of incidence and short term complication. In: Onofriescu M, Vlădăreanu R (eds). Proceedings of SOGR 2018: The $17^{\text {th }}$ National Congress of The Romanian Society of Obstetrics and Gynecology \& First Advanced Colposcopy Course, 19-22 September 2018, laşi, Romania, Filodiritto Publisher, Bologna, Italy, 2019, 708-712.

[48] Gerberding KM, Eisenhut CC, Engle WA, Cohen MD. Congenital Candida pneumonia and sepsis: a case report and review of the literature. J Perinatol, 1989, 9(2):159-161. PMID: 2661761

[49] Kozinn PJ, Taschdjian CL, Dragutsky D, Minsky A. Cutaneous candidiasis in early infancy and childhood. Pediatrics, 1957, 20(5 Pt 1):827-834. PMID: 13484321

[50] Oriel JD, Partridge BM, Denny MJ, Coleman JC. Genital yeast infections. Br Med J, 1972, 4(5843):761-764. https://doi.org/ 10.1136/bmi.4.5843.761 PMID: 4566994 PMCID: PMC1787055

[51] Maudsley RF, Brix GA, Hinton NA, Robertson EM, Bryans AM, Haust MD. Placental inflammation and infection. A prospective bacteriologic and histologic study. Am J Obstet Gynecol, 1966, 95(5):648-659. https://doi.org/10.1016/s0002-9378(16)3474 0-8 PMID: 5949478

[52] Delaplane D, Wiringa KS, Shulman ST, Yogev R. Congenital mucocutaneous candidiasis following diagnostic amniocentesis. Am J Obstet Gynecol, 1983, 147(3):342-343. https://doi.org/ 10.1016/0002-9378(83)91126-2 PMID: 6624802

[53] Whyte RK, Hussain Z, deSa D. Antenatal infections with Candida species. Arch Dis Child, 1982, 57(7):528-535. https://doi.org/10.1136/adc.57.7.528 PMID: 7103544 PMCID: PMC1627698

[54] Munteanu O, Cîrstoiu MM, Filipoiu FM, Bohîtţea RE, Bulescu IA, Berceanu C. Morphological and ultrasonographic study of fetuses with cervical hygroma. A case series. Rom J Morphol Embryol, 2016, 57(4):1421-1427. PMID: 28174814

[55] Bohîlţea RE, Tufan CF, Cîrstoiu MM, Dumitru AV, Georgescu TA Sajin M, Bodean OM, Munteanu O, Brătilă E, Ofiţeru AM, Berceanu C. Body stalk anomaly in a monochorionic-diamniotic twin pregnancy - case report and review of the literature. Rom J Morphol Embryol, 2017, 58(4):1453-1460. PMID: 29556640

[56] Bohîlţea RE, Cîrstoiu MM, lonescu CA, Niculescu-Mizil E, Vlădăreanu AM, Voican I, Dimitriu $\mathrm{M}$, Turcan N. Primary myelofibrosis and pregnancy outcomes after low molecularweight heparin administration: a case report and literature review. Medicine (Baltimore), 2017, 96(46):e8735. https:// doi.org/10.1097/MD.0000000000008735 PMID: 29145319 PMCID: PMC5704864

[57] Iordachescu AC, Cirstoiu MM, Zugravu CA, Teodor OM, Turcan N, Ducu I, Bohiltea RE. Dietary behavior during pregnancy. Exp Ther Med, 2020, 20(3):2460-2464. https:// doi.org/10.3892/etm.2020.8804 PMID: 32765734 PMCID: PMC7401895

[58] Bohiltea RE, Zugravu CA, Nemescu D, Turcan N, Paulet FP, Gherghiceanu F, Ducu I, Cirstoiu MM. Impact of obesity on the prognosis of hypertensive disorders in pregnancy. Exp Ther Med, 2020, 20(3):2423-2428. https://doi.org/10.3892/ etm.2020.8783 PMID: 32765727 PMCID: PMC7401951

[59] Bohiltea RE, Zugravu CA, Neacsu A, Navolan D, Berceanu C Nemescu D, Bodean O, Turcan N, Baros A, Cirstoiu MM. The prevalence of vitamin $D$ deficiency and its obstetrical effects. A prospective study on Romanian patients. Rev Chim (Bucharest), 2019, 70(4):1228-1233. https://doi.org/10.373 58/RC.19.4.7097

[60] Darmstadt GL, Dinulos JG, Miller Z. Congenital cutaneous candidiasis: clinical presentation, pathogenesis, and management guidelines. Pediatrics, 2000, 105(2):438-444. https:// doi.org/10.1542/peds.105.2.438 PMID: 10654973

[61] Baley JE, Kliegman RM, Fanaroff AA. Disseminated fungal infections in very low-birth-weight infants: clinical manifestations and epidemiology. Pediatrics, 1984, 73(2):144-152. PMID: 6420764

[62] Chesney PJ, Justman RA, Bogdanowicz WM. Candida meningitis in newborn infants: a review and report of combined amphotericin B-flucytosine therapy. Johns Hopkins Med J, 1978, 142(5):155-160. PMID: 651085

[63] Faix RG. Systemic Candida infections in infants in intensive care nurseries: high incidence of central nervous system involvement. J Pediatr, 1984, 105(4):616-622. https://doi.org/ 10.1016/s0022-3476(84)80433-3 PMID: 6481539

[64] Aliaga S, Clark RH, Laughon M, Walsh TJ, Hope WW, Benjamin DK, Kaufman D, Arrieta A, Benjamin DK Jr, Smith PB. Changes in the incidence of candidiasis in neonatal intensive care units. Pediatrics, 2014, 133(2):236-242. https://doi.org/ 10.1542/peds.2013-0671 PMID: 24446441 PMCID: PMC 3904270

[65] Schwartz DA, Reef S. Candida albicans placentitis and funisitis: early diagnosis of congenital candidemia by histopathologic examination of umbilical cord vessels. Pediatr Infect Dis J, 1990, 9(9):661-665. PMID: 2235191

[66] Diana A, Epiney M, Ecoffey M, Pfister RE. "White dots on the placenta and red dots on the baby": congenital cutaneous candidiasis - a rare disease of the neonate. Acta Paediatr, 2004, 93(7):996-999. https://doi.org/10.1111/j.1651-2227.20 04.tb02701.x PMID: 15303819

[67] Melville C, Kempley S, Graham J, Berry CL. Early onset systemic Candida infection in extremely preterm neonates. Eur J Pediatr, 1996, 155(10):904-906. https://doi.org/10.10 07/BF02282843 PMID: 8891563

[68] Baley JE, Silverman RA. Systemic candidiasis: cutaneous manifestations in low birth weight infants. Pediatrics, 1988, 82(2):211-215. PMID: 3399294

[69] Faix RG, Naglie RA, Barr M Jr. Intrapleural inoculation of Candida in an infant with congenital cutaneous candidiasis. Am J Perinatol, 1986, 3(2):119-122. https://doi.org/10.1055/ s-2007-999846 PMID: 3964381

[70] Pradeepkumar VK, Rajadurai VS, Tan KW. Congenital candidiasis: varied presentations. J Perinatol, 1998, 18(4):311316. PMID: 9730205

[71] Rowen JL, Tate JM. Management of neonatal candidiasis. Neonatal Candidiasis Study Group. Pediatr Infect Dis J, 1998, 17(11):1007-1011. https://doi.org/10.1097/00006454199811000-00008 PMID: 9849983 PMCID: PMC3058476

[72] Shalev E, Battino S, Romano S, Blondhaim O, Ben-Ami M. Intraamniotic infection with Candida albicans successfully treated with transcervical amnioinfusion of amphotericin. Am J Obstet Gynecol, 1994, 170(5 Pt 1):1271-1272. https://doi.org/ 10.1016/s0002-9378(94)70140-7 PMID: 8178851

\section{Corresponding authors}

Octavian Munteanu, Assistant Lecturer, MD, PhD, Department of Anatomy, Carol Davila University of Medicine and Pharmacy, Bucharest; Department of Obstetrics and Gynecology, University Emergency Hospital, 8 Eroilor Sanitari Avenue, Sector 5, 050474 Bucharest, Romania; Phone +40722-650 092, e-mail: octav_munteanu@yahoo.com Florentina Ligia Furtunescu, Associate Professor, MD, PhD, Department of Public Health and Management, Carol Davila University of Medicine and Pharmacy, 8 Eroilor Sanitari Avenue, Sector 5, 050474 Bucharest, Romania; Phone +40723-537 913, e-mail: florentina.furtunescu@umf.ro 